\title{
Avaliação de sustentabilidade do plano financeiro do regime próprio de previdência cearense
}

Sustainability assessment of the financial plan of the Ceará state's own pension scheme

\section{Tatyanne Cavalcante Pimenta Gomes ${ }^{1}$ Rômulo Alves Soares ${ }^{2}$}

\section{RESUMO}

Esta pesquisa busca analisar a sustentabilidade do regime próprio de previdência estadual, mediante a análise da solvência do respectivo sistema previdenciário, empregando modelos econométricos que mensuram sua sustentabilidade durante o período de 2014 a 2018. As variáveis utilizadas foram a receita e a despesa previdenciária; os aportes estatais e a receita corrente, extraídas dos Relatórios Resumidos de Execução Orçamentária (RREO). O modelo estatístico adotado foi a função de reação fiscal descrita por Bohn (1998), adaptada para as questões previdenciárias. Os resultados mostram que o plano financeiro do regime próprio de previdência do estado do Ceará é insolvente, dependendo de aportes estatais para complementar o total das receitas previdenciárias arrecadadas e propiciar o pagamento da folha de aposentados e pensionistas. Portanto, resta clara a necessidade de focar na busca por alternativas mais eficazes para o equacionamento do desequilíbrio previdenciário, visto que a despesa previdenciária é vultosa e a sua repercussão no ajuste fiscal do Estado é relevante.

Palavras-Chave: Sustentabilidade. Regime Próprio Previdenciário. Ceará.

\footnotetext{
1 Mestre em Administração e Controladoria pela Universidade Federal do Ceará (UFC). Bacharel em Ciências Contábeis pela Universidade Estadual do Ceará (Uece). Especialista em Fronteiras do Conhecimento em Auditoria Governamental: Desafios para o século XXI e em Direito Público, com ênfase em Direito Tributário. Atualmente é Analista de Controle Externo, com especialidade em Auditoria Governamental, no Tribunal de Contas do Estado do Ceará (TCE-CE). E-mail: taty_cav@yahoo.com.br

2 Doutorando do Programa de Pós-Graduação em Administração e Controladoria na Universidade Federal do Ceará. Membro do Laboratório de Pesquisa em Competitividade e Sustentabilidade (LECoS/UFC) e do Grupo de Pesquisa em Análise Multivariada Aplicada (Gama/UFC). Graduado em Ciências Atuariais e Mestre em Administração e Controladoria pela Universidade Federal do Ceará (2016).E-mail: romulosoares@gmail.com
} 


\section{ABSTRACT}

This research seeks to analyze the sustainability of the state pension system, by analyzing the solvency of the respective social security system, employing models econometric that measure their sustainability, from 2014 to 2018. The variables used were income and social security expenditure; state contributions and current revenue, extracted from the Summary Budget Execution Reports (RREO). The statistical model adopted was the fiscal reaction function described by Bohn (1998) adapted to social security issues. The results show that the financial plan of the Ceará state's own pension scheme is insolvent, depending on state contributions to complement the total social security revenues collected and to provide the payment of the retirees and pensioners' payroll. Therefore, it is clear that there is a need to focus on finding more effective alternatives to address the social security imbalance, as social security expenditure is large and its impact on the state's fiscal adjustment is relevant.

Keywords: Sustainability. Social Security. Ceará.

Recebido: $10-08-2020$

Aprovado: 08-10-2020

\section{INTRODUÇÃO}

A previdência brasileira consiste em política pública essencial e segue um padrão em todo o país, aplicando-se a todas as relações de trabalho, incluindo o setor público nos três níveis de governo. Subdivide-se em dois sistemas previdenciários públicos contributivos - regime geral de previdência social (RGPS) e regime próprio de previdência social (RPPS) -, além de regras específicas para contratação voluntária do regime de previdência complementar (RPC). 
Primordialmente, a função do RPPS, objeto de estudo da presente pesquisa, consiste em amparar previdenciariamente seus segurados, servidores públicos ocupantes de cargos efetivos, e respectivos dependentes, em substituição ao RGPS.

No estado do Ceará, a previdência está legalmente organizada em dois regimes. O primeiro trata do RPPS, denominado Sistema Único de Previdência Social do Estado do Ceará - SUPSEC, criado em 1999 e destinado a servidores públicos e militares estaduais, já o segundo, foi instituído em 2013, compreendendo o RPC, destinado a servidores públicos civis estaduais que ingressarem no serviço público estadual após o início de funcionamento da entidade que administrará esse RPC.

Nesse contexto, ressalta-se que as despesas decorrentes da previdência pública são vultosas e que uma gestão pública eficiente requer o equilíbrio das contas públicas. Portanto, é fundamental se manter esse equilíbrio no âmbito previdenciário para que um possível déficit não tenha repercussão no ajuste fiscal do Estado (SIMONASSI; KOURY; MATOS, 2013).

Em tal caso, o Ceará não é o único estado que passa por esse desafio. Afinal de contas, vale destacar que todo o país atravessa um momento de reforma a fim de encontrar soluções para a manutenção do sistema previdenciário.

Diante do exposto, este trabalho busca analisar a sustentabilidade do regime próprio de previdência estadual cearense. Tal estudo utilizará dados previdenciários bimestrais concernentes ao período de 2014 a 2018 e permitirá evidenciar se o referido regime é solvente ou não. Serão analisadas as contribuições do Estado e dos servidores para o fundo, o total das suas despesas, além do aporte financeiro realizado pelo estado do Ceará para que os benefícios possam ser pagos aos beneficiários de pensão e aposentadoria.

Por fim, explana-se sobre a estrutura organizacional do presen- 
te estudo, que consiste em cinco partes. Depois desta introdução, serão apresentados aspectos históricos e normativos sobre a previdência social no Brasil e em específico no Ceará. Já em seguida, será apresentada a metodologia utilizada. Após isso, será feita uma análise dos resultados encontrados e uma síntese conclusiva de todo o trabalho.

\section{ASPECTOS HISTÓRICOS E CONSTITUCIONAIS DA PREVIDÊNCIA SOCIAL}

A previdência dos servidores públicos brasileiros é marcada em seu processo evolutivo por diversas alterações na legislação, culminando, recentemente, em significativas reformas previdenciárias, as quais serão brevemente explanadas nesta seção.

Antes mesmo da Constituição Federal de 1988, no Brasil, já havia referência à proteção previdenciária dos servidores públicos na Constituição de 1891, contudo, tratava-se apenas da aposentadoria por invalidez: "Art. 75 - A aposentadoria só poderá ser dada aos funcionários públicos em caso de invalidez no serviço da Nação".

Segundo Campos (2010), a Constituição de 1934 acrescentou a aposentadoria compulsória por idade dos funcionários públicos, estabelecendo um conjunto de regras para elegibilidade à aposentadoria e para o cálculo de seus proventos, e a aposentadoria para os juízes e parlamentares.

Por outro lado, a Constituição de 1937 adotou redação praticamente idêntica à anterior em seu artigo 156, além disso normatizou em seu artigo 177 a possibilidade de aposentadoria compulsória por interesse do serviço público ou por conveniência do regime (NOGUEIRA, 2012):

Art. 177 - Dentro do prazo de sessenta dias, a contar da data desta Constituição, poderão ser aposentados ou reformados de acordo com a legislação em vigor os funcionários civis e militares cujo afastamento se impuser, a juízo exclusivo do Governo, no interesse do serviço público ou por conveniência do regime. 
A criação do Instituto de Previdência e Assistência dos Servidores do Estado (Ipase), forma de sistema mais organizada e unificada que compreendia servidores públicos federais dos três poderes, só veio a acontecer em 1938, por meio do Decreto-Lei n ${ }^{\circ} 288$. O Ipase, posteriormente extinto em 1977, era responsável por assegurar o benefício da aposentadoria aos seus participantes. Mas de fato, sua função consistia apenas em repassar o valor recebido mensalmente do Tesouro Nacional, o qual exercia o papel de verdadeiro responsável financeiro (NOGUEIRA, 2012).

Posteriormente, as Constituições, inclusive a de 1988, em sua forma original, abordaram de forma cada vez mais detalhada os critérios de concessão das aposentadorias dos servidores públicos, mas não explanavam sobre o custeio correspondente, não sendo, desse modo, caracterizado em nenhuma delas a figura de um regime previdenciário (MELO, 2016).

Deste modo, a Constituição de 1988, no texto original de seu art. 40, manteve o modelo encontrado em Constituições anteriores, limitandose a definir as condições de acesso aos benefícios de aposentadoria e pensão por morte, sem contudo estabelecer a forma de custeio e a sistemática para manutenção do equilíbrio entre as receitas e despesas, permanecendo, portanto, o vácuo legislativo no que diz respeito aos critérios a serem observados para a organização do regime de previdência dos servidores (NOGUEIRA, 2012).

Nesse esteio, em seu art. 39, a Carta Magna vigente à época determinou a adoção de regime jurídico único para a contratação dos servidores, cuja regulamentação foi dada pela Lei n ${ }^{\circ}$ 8.112/1990 que alterou o regime antes subordinado à Consolidação das Leis Trabalhistas (CLT) para o regime estatutário. Nesse período, um expressivo número de servidores, admitidos anteriormente sem prévio concurso público, foi efetivado e seus cargos tornaram-se públicos.

Tal situação coadunou-se com a rápida expansão dos RPPS nos estados e municípios e, consequentemente, o aumento das despesas com 
pessoal e a extensão dos critérios de aposentadoria para os servidores públicos, gerando um grande passivo atuarial (MELO, 2016).

Entretanto, na perspectiva de aprimorar os RPPS, a Emenda Constitucional (EC) $\mathrm{n}^{\mathrm{o}} 3$ estabeleceu que as aposentadorias e pensões dos servidores públicos federais seriam custeadas por recursos provenientes da União e das contribuições dos servidores (FERRARO, 2010). Dessa forma, foi instituído o vínculo contributivo para as aposentadorias, em substituição à ideia de prêmio concedido pela relação de trabalho (NOGUEIRA, 2012).

Vale ressaltar que até essa data não havia sido editada legislação que previsse a adoção de métodos de equacionamento em caso de déficit no resultado apurado do regime próprio previdenciário.

Nesse contexto, a Lei $n^{0} 8.688 / 1993$ incorporou essa obrigatoriedade ao artigo 231 da Lei $n^{\circ} 8.112 / 1990$ e instituiu a contribuição para o Plano de Seguridade Social do servidor público federal e a destinação de recursos adicionais para a cobertura da insuficiência financeira resultante da diferença entre as despesas e as receitas para a União, suas autarquias e fundações (NOGUEIRA, 2012), in verbis:

\footnotetext{
Art. $3^{\circ}$ A União, as autarquias e as fundações públicas federais participarão do custeio do Plano de Seguridade Social do servidor através de:

I - contribuição mensal, com recursos do Orçamento Fiscal, de valor idêntico à contribuição de cada servidor, conforme definida no art. $2^{\circ}$;

II - recursos adicionais, quando necessários, em montante igual à diferença entre as despesas relativas ao plano e as receitas provenientes da contribuição dos servidores e da contribuição a que se refere o inciso I, respeitado o disposto no art. 17 da Lei $\mathrm{n}^{\mathrm{o}} 8.212$, de 24 de julho de 1991.
}

Cinco anos depois, fora aprovada a Emenda Constitucional $\mathrm{n}^{\mathrm{o}}$ 20/1998, que conforme Campos (2010), surgiu da necessidade de uniformizar os diversos regimes próprios de previdência dos entes federativos e 
foi a base da reestruturação do sistema constitucional de previdência social dos servidores públicos, acompanhada pelas Leis 9.717/98 e 9.796/99.

Por meio dessa emenda a redação do caput do artigo 40 da Constituição foi alterada e a exclusividade da aplicação do RPPS aos servidores titulares de cargos efetivos das unidades federativas, em cargo público, sob regime estatutário e mediante aprovação em concurso público restou sacramentada (NOGUEIRA, 2012).

Resumidamente, elencam-se as principais alterações que a referida emenda trouxe à previdência do servidor público (BRASIL, 1998):

a) obrigatoriedade de RPPS único para cada unidade federativa;

b) instituição do regime contributivo e da necessidade de equilíbrio financeiro e atuarial do regime próprio;

c) idade mínima como requisito de elegibilidade para aposentadoria por tempo de contribuição e estabelecimento de tempo mínimo de efetivo exercício no serviço público e no cargo de referência para a aposentadoria;

d) os valores dos proventos de aposentadoria ou pensão foram limitados ao valor da remuneração do servidor no cargo em que este se aposentou ou que serviu de base para a concessão da pensão;

e) proibição de recebimento simultâneo de proventos de aposentadoria com remuneração de cargo, emprego ou função pública e da percepção de mais de uma aposentadoria à conta do RPPS, com exceção dos cargos acumuláveis na forma da Constituição;

f) previsão de contenção dos benefícios no âmbito do regime próprio de previdência ao teto do RGPS nos casos de a União, os Estados, o Distrito Federal ou os Municípios instituírem regime de previdência complementar.

Campos (2010) afirma ainda que a Emenda Constitucional $\mathrm{n}^{\circ}$ 20/1998 não alterou os critérios de cálculo e de reajuste dos valores da aposentadoria e pensão, bem como não definiu as regras para a administração do RPPS. Tais normas ficaram a cargo da Lei 9.717/1998, editada 
logo antes, a qual estabelecia os diversos parâmetros e diretrizes gerais para a organização dos RPPS e para estrutura dos respectivos gestores.

Cumpre registrar a descrição da relação do servidor público com o Estado e o significado, naquela época, de aposentadoria elaborada por Bianco et al. (2009):

O relacionamento do servidor com o Estado era visto, até as recentes reformas constitucionais, como uma relação pro labore fato. Uma vez admitido no serviço público, o indivíduo ganhava um novo status, o de "servidor público", que carregava consigo até a morte. Não havia "aposentadoria" propriamente dita; o servidor nunca deixava de ser servidor. Havia, isto sim, a passagem para a inatividade. Chegado certo momento, o indivíduo não mais necessitava trabalhar. Continuava com todos os direitos e prerrogativas, sem alteração em sua remuneração, e permanecia com certas obrigações, que se feridas, poderiam acarretar a cassação de sua aposentadoria.

No intuito de ajustar essa realidade, a Emenda Constitucional $\mathrm{n}^{\mathrm{o}}$ 41/2003 alterou o caput do art. 40 da Carta Magna, insculpindo o princípio da solidariedade à previdência dos servidores públicos, tendo em vista que estabelece que os entes, os servidores ativos e inativos e os pensionistas serão os responsáveis pelas contribuições consignadas ao regime próprio (FERRARO, 2010).

$\mathrm{Na}$ obra de Bianco et al (2009) enuncia-se que essa emenda aproximou as regras de benefícios dos RPPS àquelas aplicadas pelo RGPS e alterou significativamente a forma de cálculo e de reajuste dos proventos sem, entretanto, alterar os requisitos de elegibilidade da aposentadoria do servidor público.

As principais alterações advindas da EC n ${ }^{\circ}$ 41/2003 são:

a) instituição do princípio da solidariedade entre Ente e servidores quanto ao caráter contributivo;

b) o cálculo dos benefícios que passam a ser baseados na média dos salários de contribuição e no caso de pensão o cálculo segue a me- 
todologia de que até o teto do RGPS recebe-se o valor integral e quando ultrapassar esse limite máximo, paga-se $70 \%$ do valor excedente;

c) a alíquota de contribuição previdenciária para os servidores, obrigatoriamente, deve ser no mínimo igual à praticada pela União;

d) criação do abono de permanência, benefício pecuniário, no valor da contribuição previdenciária, pago ao servidor elegível para a aposentadoria voluntária, mas que opta por não se aposentar, obedecendo a idade para aposentadoria compulsória;

e) ratificação da vedação de existência de mais de um RPPS para cada ente e proibição de mais de uma unidade gestora para cada regime próprio;

f) extinção das regras que faziam referência à previdência dos militares, até então, no artigo 40 da Constituição, direcionando a sua disciplina para a legislação ordinária (NOGUEIRA, 2012);

g) a redação do $\S 15$ do artigo 40, passou a estabelecer novas regras de instituição de regime de previdência complementar pelo ente federativo, para seus servidores, por meio de lei e que os planos de benefícios deveriam prever a modalidade de contribuição (NOGUEIRA, 2012).

No ano de 2005, nova Emenda Constitucional fora aprovada com impactos na normatização dos RPPS, trata-se da EC n ${ }^{\circ} 47 / 2005$, que criou uma nova regra transitória para o benefício de aposentadoria com proventos equivalentes à última remuneração e mais uma exceção à incidência das contribuições previdenciárias, aplicando retroativamente a 31 de dezembro de 2003, data de publicação da EC nº 41/2003. Consoante, Bianco et al (2009) assim ficou regulamentada a situação daqueles segurados atingidos por essas emendas:

A integralidade e a paridade foram mantidas para os benefícios concedidos até 31.12.2003, para os servidores com direito adquirido até aquela data, para as aposentadorias por idade e tempo de contribuição que atendam aos requisitos das regras transitórias do artigo $6^{\circ}$ da Emenda Constitucional n ${ }^{\circ} 41 / 2003$ 
ou do artigo $3^{\circ}$ da Emenda Constitucional $n^{\circ} 47 / 2005$ e para as pensões que decorram do falecimento de servidores aposentados com fundamento nesta última regra (BIANCO et al., 2009).

Ademais, há pouco tempo, foram aprovadas substanciais mudanças na previdência social por meio da $\mathrm{EC}^{\circ}$ 6/2019. Dentre as principais medidas dessa reforma da previdência enumeradas pela Secretaria da Previdência - SPREV (2019) estão:

a) fixação de uma idade mínima (65 anos para homens e 62 anos para mulheres) para a aposentadoria;

b) novo regramento de cálculo das aposentadorias: corresponderão a $60 \%$ da média de todas as remunerações acrescidos de $2 \%$ para cada ano que exceder o mínimo de anos de contribuição.

Dessa forma, a Emenda Constitucional n ${ }^{\circ}$ 6/2019 encerra, até a presente data, a recente evolução histórica das reformas constitucionais da previdência social no âmbito federal brasileiro, ao passo que está em trâmite no Congresso Nacional a Proposta de Emenda à Constituição (PEC) $n^{\circ}$ 133/2019, comumente chamada de PEC Paralela, que foi desmembrada do primeiro texto, para não atrasar a sua aprovação, e inclui estados e municípios na reforma; prevê novas receitas para a Previdência; e faz uma revisão das intervenções da PEC 6/2019 sobre benefícios assistenciais (AGÊNCIA SENADO, 2019).

No Ceará, o RPPS é denominado de Sistema Único de Previdência Social do Estado do Ceará - SUPSEC, instituído pela Lei Complementar estadual $n^{\circ} 12 / 1999$, que assegura aos seus segurados a concessão dos benefícios de aposentadoria e pensão por morte previstos no art. 40 da Constituição Federal de 1988 (SEPLAG/CE, 2018).

Como órgão gestor do SUPSEC elenca-se a Secretaria do Planejamento e Gestão - SEPLAG, enquanto não for constituída entidade com personalidade jurídica para essa finalidade. Tem-se por representante legal do Sistema o Secretário do Planejamento e Gestão. A Procuradoria-Geral do Estado é responsável pela análise e aplicação da matéria legal e jurídica 
no âmbito do SUPSEC (SEPLAG/CE, 2018).

No tocante aos órgãos reguladores e fiscalizadores, no âmbito federal, tem-se a Secretaria de Previdência (SPREV) do Ministério da Economia que regula e fiscaliza as atividades relacionadas ao SUPSEC. No âmbito estadual, fiscalizam o SUPSEC a Controladoria-Geral do Estado - CGE e o Tribunal de Contas do Estado - TCE (SEPLAG/CE, 2018).

\section{METODOLOGIA}

Esta seção expõe a metodologia adotada neste trabalho, descrevendo a fonte de coleta e as técnicas aplicadas para o tratamento dos dados, bem como para a interpretação dos resultados.

De início, por meio de sites institucionais do Governo do Estado do Ceará, website da Secretaria da Fazenda (SEFAZ) e portal da transparência, foram coletados os dados utilizados neste trabalho, quais sejam são a receita previdenciária, despesa previdenciária, aporte do Estado para cobertura de déficits e o total da receita corrente.

O escopo de análise dessas variáveis, que possuem frequência bimestral, corresponde ao período de 2014 até 2018, com um total de 30 observações. A coleta dos dados foi realizada em consulta aos anexos I e IV do Relatório Resumido da Execução Orçamentária (RREO).

Além das variáveis supracitadas, também foram calculadas as variáveis da receita e da despesa filtradas, utilizando o filtro Hodrick Prescott - HP, no intuito de mensurar o desvio da receita e da despesa, respectivamente.

Vale destacar que há uma premissa importante associada ao conjunto de variáveis financeiras utilizadas na presente pesquisa. Refere-se ao princípio financeiro do valor presente, no qual todos os valores monetários devem representar o quantum em um período específico.

Dessa forma, considerando que as variáveis financeiras utilizadas foram compiladas em termos nominais enquanto o modelo econométrico, 
utilizado neste trabalho, necessita de termos reais, foi preciso deflacionar as variáveis pelo Índice Nacional de Preços ao Consumidor (INPC), a preço do último mês do período de análise, visto que, no caso brasileiro, esse índice tem maior relação com a cesta de consumo típica dos ativos e aposentados (SIMONASSI; KOURY; MATOS, 2013).

Neste trabalho, a metodologia adotada para testar a solvência da previdência pública do Ceará está fundada na estimação da função de reação fiscal, conforme descrita por Bohn (1998), cuja técnica utilizada consiste em estimar a seguinte equação:

\section{SUPREVRECORR $t=f\left(D E B R C O R R_{t-1}\right.$, DESVREC, DESVDESP, $)$}

O Superávit ou déficit previdenciário está relacionado com o montante das receitas ou despesas previdenciárias, bem como com a dívida no período anterior. O Resultado previdenciário (SUPREVRECORR) é a variável dependente. DEBRCORR, DESVREC e DESVDESP são as variáveis explicativas. Espera-se relação direta entre a variável dependente e cada uma das explicativas. A forma matemática estatística é dada pela seguinte equação linear e sua composição é explicitada no Quadro 1:

\section{SUPREVRECORR $=\beta_{0}+\beta_{t}$ DEBRCORR $R_{t-1}+\beta_{2}$ DESVREC $t+\beta_{3}$ DESVDESP ${ }_{t}+\varepsilon_{t}$}

Quadro 1: Composição da Equação Linear adotada nesta pesquisa

\begin{tabular}{|c|c|}
\hline SUPREVRECORR & $=($ Resultado do saldo previdenciário / Receita Corrente $)$ \\
\hline DEBRCORR & $=($ Aporte de Recurso do Estado / Receita Corrente $)$ \\
\hline DESVREC & $=($ Receita Previdenciária $/$ Receita Corrente $)-$ Receita Filtrada $^{1}$ \\
\hline DESVDESP & $=($ Despesa Previdenciária $/$ Receita Corrente $)-$ Despesa Filtrada $^{1}$ \\
\hline$\beta 0$ & $=$ coeficiente linear ou intercepto, a ser estimado \\
\hline$\beta 1, \beta 2$ e $\beta 3$ & $=$ respectivos coeficientes angulares de cada variável explicativa \\
\hline$\varepsilon$ & $=$ termo estocástico \\
\hline
\end{tabular}

Fonte: Adaptado de Simonassi, Koury e Matos (2013).

${ }^{1}$ Receita e Despesa com aplicação do filtro Hodrick Prescott - HP. 
Ademais, foi aplicado em fase preliminar o teste de raiz unitária Dickey-Fuller Ampliado (ADF), com intercepto, pressupondo que há dívida no período anterior. Esse teste consiste em analisar a estacionariedade na série bimestral de déficit previdenciário corrente.

Por outro lado, o teste de normalidade dos resíduos, o teste de homoscedasticidade dos resíduos, o teste de independência dos resíduos e a verificação de existência de multicolinearidade também foram empregados a fim de assegurar a acurácia do modelo.

Cabe ainda destacar que, diante do cenário de segregação de massas ocorrido no estado do Ceará no ano de 2013, atualmente, o sistema previdenciário cearense conta com dois planos: o financeiro e o previdenciário. Desse modo, este estudo se ateve ao plano financeiro, tendo em vista que até a presente data não ocorreu resultado previdenciário negativo, bem como aporte estatal, uma das variáveis que compõe o rol da equação estatística adotada, no âmbito do plano previdenciário.

No intuito de ilustrar a situação do plano financeiro do regime próprio de previdência do estado Ceará, elaborou-se a Tabela 1 com base nos dados extraídos dos RREOS, referentes ao período sob análise. 
Tabela 1: Variáveis utilizadas neste estudo

\begin{tabular}{|c|c|c|c|c|c|}
\hline Flano Finanaceirs & Receita Previdenciaris & Despena Previde neidia & Resultade Previdencialib & Aporte Estatal & Receita Comente \\
\hline 2014.1 & RS 191 333.819 .49 & RS 365.202 .033 .78 & \begin{tabular}{|l|l|}
-RS 173.265 .214 .29 \\
\end{tabular} & RS 132098.398 .75 & RS 3.327 .007 .467 .79 \\
\hline 2014.2 & RS 177961.96011 & RS $388921.551,19$ & -RS 190969.991 .08 & RS 150.222512 .94 & RS 2764.156.804.42 \\
\hline 2014.3 & RS $206.175 .212,34$ & RS $462418.7 \times 6.34$ & $-R S 236.243 .54400$ & R5 258.771 .35252 & R5 3.036 .784 .524 .17 \\
\hline 2014.4 & RS 21700345887 & RS 571.157 .964 .58 & $-\mathrm{kS} 154$ gi4 5xa71 & RS $162,065,44384$ & RS 29120056000 \\
\hline 2014.5 & RS 211.902 .40211 & RS 374.271 .85691 & $-R 516239.46 .90$ & R5 $168.312607,99$ & RS 2.892 .553 .515 .61 \\
\hline 2014.6 & RS $\$ 90559792922$ & RS s7rogx 90003 & -2850.471 .04081 & R.5 163.198 .50000 & RS $3565,021.067,14$ \\
\hline 2015.1 & RS 132.123 .56360 & RS 407.067 .852 .66 & -RS 274.254.28906 & RS 181.447 .246 .26 & R5.3.339.238.34.18 \\
\hline 2015.2 & RS $225.600 .377,37$ & RS $411.129,409,46$ & -RS 185529.03200 & RS 200.493.54351 & RS 3.203 .698 .180 .61 \\
\hline $2015-3$ & RS 213.929.21189 & RS 414.119 .072 .93 & -1.5200 .189 .861 .06 & RS 205.812.432.63 & RS 3.193.\$84.73234 \\
\hline 2015.4 & RS 219.009.354.88 & RS 520.905.718.14 & -RS 301.716 .363 .26 & RS 304.466 .86862 & RS 3.042 .009 .134 .92 \\
\hline 2015.5 & RS 223.475.512.06 & R5 422.982.859.40 & $-R 5190 \times 07.44724$ & RS 211.963 .89155 & RS $30030,379,332,72$ \\
\hline 2015.6 & RS 267403556,37 & R5 533.75852537 & -RS 71.26496000 & RS $110087,960,76$ & R5 $4242050065 \times 5$ \\
\hline 2016.1 & RS 254779.65523 & R5 4445185631 & -RS 170 7la 900 10 & RS $13009 \times 175,96$ & RS 3691.525 .67320 \\
\hline 2016.2 & RS $174 \times 65$.89095 & R5 428.997.146.83 & -125.263 .531 .255 .88 & ItE.252.583.475.45 & R.5.3.404.008.354.76 \\
\hline 2016.3 & RS $223.477 \times 00073$ & RS $443.368 .42 \times 28$ & -RS 219.050 .62755 & RS 220.757.445,90 & R5. 3.591 .978 .127 .12 \\
\hline 2016.4 & RS 216.912.09055 & RS 558.233 .31400 & -RS 341321.273 .54 & RS 358.789 .789 .92 & RS 3.500 .712 .155 .19 \\
\hline 2016.5 & RS 225.166 .416 .28 & RS 452.809.571.99 & -RS 227.643.155,71 & RS 214.139.781,50 & R5 3.292 .628 .96451 \\
\hline 2016.6 & RS $440807.431,31$ & RS 571.996 .800524 & -RS 131.189371 .93 & RS 255.866 .316 .10 & RS 5000.173 .544 .00 \\
\hline 2017.1 & RS 1302868.37647 & R5 462.062 .95561 & -R5 331.775 609.14 & R5 $208590.175,06$ & RS 3.891.022.53961 \\
\hline 2017.2 & RS 230542.59039 & R5 481.913 .400 .43 & $-R .5 .251 .370 .80954$ & R.5.252.011.104.38 & R.5.3.515.172005.11 \\
\hline 2017.3 & RS $258,504,361,10$ & R5 47x.3to.s64a? & -RS. 219 506.503.12 & RS.223.1R4.19124 & RS 3.953 ans.139.55 \\
\hline 2017.4 & RS 255031.946 .80 & RS 452.090 .15705 & -RS 194.903 .221 .25 & RS 343.732 .05752 & R5 3.480 .695 .625 .19 \\
\hline 2017.5 & RS $256,513,465,14$ & RS 634.933.93405 & -RS 3900 575.457 .26 & RS 237.661.90894 & R5 3.533 .157 .322 .76 \\
\hline 2017.6 & RSS $\triangle 59.605 .227,41$ & RS 611.307 .008 .35 & -RS 141.701.781,00 & RES 282034891,77 & RS 4.496 .080 .394 .18 \\
\hline 2018.1 & RS 183.154 .514 .96 & RS $492.752 .4 \times 0.36$ & RS 300 597.975,40 & KS 198.158.111.81 & RS 4.167.632.96273 \\
\hline 2018.2 & RS 297.118 .655 .45 & R5 520.842 .87084 & -0.223 .724 .215 .39 & R5 $213.752 .926,05$ & RS 3800.432 .63205 \\
\hline 2018.3 & RS 296001.119 .38 & R5.517.254.765.83 & $-R 5.230623 .626 .45$ & R.5 23032257978 & RS 3.978 .442007 .81 \\
\hline 2018.4 & RS $\times 2 \times$ tos 56109 & R5 6.55.154.70804 & $-R 5.46969 .22502$ & RS 3752 V) 66420 & R5 $38.62757 \times 644$ \\
\hline 2018.5 & RS 285844086,64 & RS 523.687 .83769 & -R.5.227.843.751.05 & RES 231374,31092 & RS 4010.645 .83858 \\
\hline 2018.6 & RS 436.468 .17464 & RS 662.885.557.99 & -RS 226.117 .392 .95 & RS 253.457 .781 .99 & RS 5.000 .877 .45205 \\
\hline
\end{tabular}

Fonte: Elaborada pelos autores (2019) com dados do RREO.

Diante do exposto, pode-se observar que as receitas previdenciárias não são suficientes para suprir a demanda relativa ao pagamento das despesas previdenciárias. Portanto, faz-se necessário que o Estado periodicamente aporte recursos para que os segurados continuem a receber mensalmente seus benefícios.

\section{ANÁLISE DOS RESULTADOS}

A questão de pesquisa deste trabalho objetiva analisar a solvência do plano financeiro do regime próprio previdenciário cearense por meio da função de reação fiscal, aplicada por Bohn (1998). Nesse intuito, será verificada também a estacionariedade mediante o teste preliminar de raiz unitária Dickey-Fuller Ampliado (ADF). 
Conforme Simonassi, Koury e Matos (2013), a metodologia utilizada consegue captar a resposta, tanto positiva quanto a negativa, na geração de superávit primário no período corrente quando há um choque na dívida pública no período anterior. Além disso, ela também está bem especificada econometricamente para eventuais quebras estruturais e de sazonalidade. Destaca-se que a função resposta proposta por Bohn (1998), inicialmente, era associada a problemas fiscais, porém foi adaptada para questões previdenciárias.

Para o teste de raiz unitária Dickey-Fuller Ampliado (ADF) do saldo previdenciário encontrou-se o resultado apresentado na Tabela 2.

Tabela 2: Teste Dickey-Fuller Ampliado (ADF)

\begin{tabular}{c|c|c|c|}
\hline Variável & Estatística de Teste & Valor $\mathbf{P}$ & Resultado \\
\hline Saldo Previdenciário & $-4,283$ & 0,0121 & Série Estacionária \\
\hline
\end{tabular}

Fonte: Elaborada pelos autores (2019).

Ademais, também foram realizados o teste de normalidade dos resíduos, o teste de homoscedasticidade dos resíduos e o teste de independência dos resíduos com o fito de assegurar a acurácia do modelo. Considerando que os resultados foram satisfatórios, tem-se um modelo que atende aos pressupostos, conforme consta na Tabela 3 .

Destaca-se ainda que se analisou a existência de multicolinearidade entre as variáveis independentes por meio do fator de inflação da variância (VIF). Quando os valores de VIF são inferiores a 10, indicam que não há sobreposição entre as variáveis independentes, ou seja, não existe problemas de multicolinearidade, como ocorre na presente pesquisa. Os valores encontrados para cada variável são apresentados na Tabela 4. 
Tabela 3: Testes de Alinhamento do Modelo

\begin{tabular}{c|c|c}
\hline Teste & Valor P & Resultado \\
\hline Normalidade dos resíduos (Shapiro-Wilk) & 0,210 & OK \\
\hline Independência dos resíduos (Durbin-Watson) & 0,987 & OK \\
\hline Homoscedasticidade dos resíduos (Breusch-Pagan) & 0,394 & OK \\
\hline
\end{tabular}

Fonte: Elaborada pelos autores (2019).

Tabela 4: Multicolinearidade

\begin{tabular}{c|c}
\hline Variáveis & VIF (Multicolinearidade) \\
\hline DEBRCORR & 1,846 \\
\hline DESVREC & 1,032 \\
\hline DESVDESP & 1,889 \\
\hline
\end{tabular}

Fonte: Elaborada pelos autores (2019).

No presente estudo, foi feita a estimação apenas para o plano financeiro, tendo em vista que até a presente data não ocorreu resultado previdenciário negativo, bem como aporte estatal, uma das variáveis que compõe o rol da equação estatística adotada, no âmbito do plano previdenciário.

Para tanto, utilizou-se a regressão por MQO (Mínimos Quadrados Ordinários), cujos resultados são apresentados nas Tabelas 5 e 6.

Tabela 5: Regressão por MQO

\begin{tabular}{c|c|c|c}
\hline Variáveis & Estimate & T value & $\operatorname{Pr}(>|\mathbf{t}|)$ \\
\hline Intercepto & 0,033 & 1,289 & 0,209 \\
\hline DEBRCORR & $-0,445$ & $-1,941$ & 0,063 \\
\hline DESVREC & 1,349 & 1,467 & 0,154 \\
\hline DESVDESP & $-0,559$ & $-2,255$ & 0,033 \\
\hline
\end{tabular}

Fonte: Elaborada pelos autores (2019).

Tabela 6: Medidas de adequação do modelo

\begin{tabular}{c|c}
\hline TESTE $\mathbf{F}$ & $9,276(0,000)$ \\
\hline $\mathbf{R}^{2}$ & 0,517 \\
\hline $\mathbf{R}^{2}$ ajustado & 0,461 \\
\hline
\end{tabular}

Fonte: Elaborada pelos autores (2019). 
Por meio do teste de significância individual (teste "t") nos parâmetros do modelo, foi possível constatar que duas variáveis são significantes, caso seja considerado um nível de confiança de $90 \%$. Portanto, as variáveis DEBRCORR e DESVDESP são relevantes para explicar o Saldo Previdenciário do RPPS do Estado do Ceará. No que se refere ao teste de significância global (teste "F"), percebe-se que houve a rejeição da hipótese nula, indicando que o modelo é válido.

Além disso, também pode-se verificar que o modelo possui poder de explicação (R2) próximo a 50\%, ou seja, o percentual das variações da variável dependente é explicado pelas variáveis independentes do modelo, em um percentual bastante representativo.

Destaca-se que para a situação previdenciária ser considerada solvente, o coeficiente angular $\beta 1$ deveria ser superior a 0 (zero), contudo, essa não foi a grandeza encontrada. Bem como pôde-se perceber estatisticamente uma evidência de insolvência do RPPS dos Servidores do Estado do Ceará, para o período analisado, anos de 2014 a 2018, visto a redução do Saldo Previdenciário em $\mathrm{t}$, quando de um aumento em $\mathrm{t}-1$ da dívida previdenciária acumulada, ou seja, $\beta 1<0$.

Dessa forma, o cálculo de sustentabilidade do plano financeiro do regime próprio previdenciário cearense por meio da função de reação fiscal, aplicada por Bohn (1998), constatou estatisticamente uma situação de insolvência no período de 2014 a 2018.

\section{CONCLUSÃO}

Este estudo verificou o quadro deficitário do plano financeiro do regime próprio de previdência cearense, visto que por meio das variáveis coletadas e os resultados encontrados evidenciou-se a sua insolvência, no período de 2014 a 2018. Salienta-se, portanto, que as condições encontradas não se apresentam como possíveis ou suportáveis ao longo do tempo (ou seja, não são sustentáveis). 
Tal situação enseja em aportes mensais de uma grande quantidade de recursos que poderiam ser empregados em outras políticas públicas, para complementar o total das receitas previdenciárias arrecadadas e propiciar o pagamento da folha de aposentados e pensionistas.

Vislumbrou-se também que essa conjuntura obriga o governo a alocar significativa parcela do Produto Interno Bruto (PIB) em previdência a fim de zelar pela manutenção das despesas previdenciárias ao invés de realizar investimentos, comprometendo sua margem em relação à receita corrente líquida.

Em que pese o atendimento de questões sociais, tal situação é onerosa quando representa a não aplicação de recursos em atividades geradoras de retornos mais expressivos ao crescimento do Ceará, representando um custo fiscal considerável para a sociedade e tornando-se imprescindível ponderar se esse sistema é capaz de apresentar reações positivas na tentativa de equilibrar-se por conta própria, ou ao menos reduzir sua dependência do estado.

Considerando a aprovação da Lei Estadual n ${ }^{\circ}$ 123/2013, que dispôs sobre o equacionamento do déficit atuarial e a instituição do regime de previdência complementar, o Estado do Ceará realizou a segregação de massas. Com isso, ocorreu o surgimento do Plano de Custeio Previdenciário do SUPSEC, que financia os benefícios previdenciários aos seus segurados ingressos no serviço público estadual a contar do dia $1^{\circ}$ de janeiro de 2014, e que vem se mostrando superavitário.

Contudo, no Plano de Custeio Financeiro do SUPSEC permanece o dever de financiar os benefícios previdenciários do sistema que forem destinados aos segurados ativos que ingressaram no Serviço Público Estadual até o dia 31 de dezembro de 2013, aos segurados inativos e aos pensionistas em fruição de benefício na data de 31 de dezembro de 2013.

Dessa forma, ressalta-se que as formas de equacionamento consistem em ferramentas necessárias para o alcance do equilíbrio financeiro e 
atuarial da maioria dos RPPS, sendo a segregação da massa a medida mais implantada, uma vez que proporciona melhor sustentabilidade para o plano previdenciário. Entretanto, é essencial destacar que o déficit do plano financeiro, oriundo do antigo regime orçamentário, é de responsabilidade do ente público e, portanto, essa problemática persiste.

Por outro lado, cabe destacar, para o equilíbrio dos RPPS e das contas públicas, que é de fundamental importância a conservação da segregação de massa. Uma vez que esta é implementada, desequilíbrios orçamentários conjunturais não podem justificar sua revogação, visto que sua adoção tem o propósito de estar de acordo com os princípios da boa técnica definidos pela Ciência Atuarial e objetiva construir o equilíbrio financeiro e atuarial do regime de previdência dos servidores públicos.

Diante desse cenário, esta pesquisa explicitou um dos principais desafios, atualmente, enfrentado pelo RPPS do estado do Ceará, visto que as mudanças ocorridas, a partir do exercício de 2013, tornaram o seu plano financeiro cada vez mais dependente de aportes estatais e a revogação da segregação de massas não se apresenta como uma solução assertiva. Dito isso, resta clara a necessidade de focar na busca por alternativas mais eficazes para o equacionamento do desequilíbrio das suas contas.

Por fim, apresenta-se como limitação desse estudo a ausência de decomposição dos dados em FUNAPREV e Previdência Militar, pois estes apresentam características muito diferentes. Nesse contexto, indica-se como sugestão de pesquisa futura o uso de uma série temporal mais longa e revisitar a análise dos dados do SUPSEC decompostos em FUNAPREV e PREVMILITAR. 


\section{REFERÊNCIAS}

AGÊNCIA SENADO. Congresso promulga reforma da Previdência nesta terça-feira. Senado Notícias, Brasília, DF, 8 nov. 2019. Disponível em: https://bityli.com/FuFKg. Acesso em: 10 nov. 2019.

BIANCO, D. D. et al. Previdência de servidores públicos. São Paulo: Altas, 2009.

BOHN, H. The behavior of US public debt and deficits. Quarterly Journal of Economics, Cambridge, v. 113, p. 949-963, 1998.

BRASIL. Emenda Constitucional n ${ }^{\circ} 20$, de 15 de dezembro de 1998. Modifica o sistema de previdência social, estabelece normas de transição e dá outras providências. Diário Oficial da União, Brasília, DF, 16 dez. 1998.

BRASIL. Lei n 9 9.717, de 27 de novembro de 1998. Dispões sobre regras gerais para a organização e funcionamento dos regimes próprios de previdência social dos servidores públicos da União, dos Estados, do Distrito Federal e dos Municípios, dos militares dos Estados e do Distrito Federal e dá outras providências. Diário Oficial da União, Brasília, DF, 28 nov. 1998.

BRASIL. Emenda Constitucional n ${ }^{\circ}$ 41, de 19 de dezembro de 2003. Modifica os arts. 37, 40, 42, 48, 96, 149 e 201 da Constituição Federal, revoga o inciso IX do $\S 3$ do art. 142 da Constituição Federal e dispositivos da Emenda Constitucional n 20, de 15 de dezembro de 1998, e dá outras providências. Diário Oficial da União, Brasília, DF, 31 dez. 2003.

BRASIL. Emenda Constitucional n ${ }^{\circ}$ 47/, de 5 de julho de 2005. Altera os arts. 37, 40, 195 e 201 da Constituição Federal, para dispor sobre a previdência social, e dá outras providências. Diário Oficial da União, Brasília, DF, 6 jul. 2005. 
CAMPOS, M. B. L. B. Regime próprio de Previdência Social dos servidores públicos. 3. ed. São Paulo: Juruá, 2010.

FERRARO, S. A. O equilíbrio financeiro e atuarial nos regimes de previdência social. Rio de Janeiro: Lumen Juris, 2010.

MELO, A. C. RPPS dos governos estaduais do Brasil: uma análise da situação financeira e atuarial sob a ótica dos métodos de equacionamento implementados. 2016. Monografia (Graduação em Ciências Atuárias) Faculdade de Economia, Administração, Atuária e Contabilidade, Universidade Federal do Ceará, Fortaleza, 2016.

NOGUEIRA, N. G. O equilíbrio financeiro e atuarial dos RPPS: de princípio constitucional a política de estado. Coleção Previdência Social, Brasília, DF, v. 34, 2012.

SIMONASSI, A. G.; KOURY, F. J. F.; MATOS, P. R. F. Uma Função de Reação para a Análise da Sustentabilidade do Regime Próprio de Previdência Social dos Servidores do Estado do Ceará no período 20032012. Revista Controle, Fortaleza, v. 11, n. 2, p. 47-62, 2013.

SECRETARIA DE PLANEJAMENTO E GESTÃO DO ESTADO DO CEARÁ. Cartilha da Previdência do Estado do Ceará. Fortaleza: Seplag, c2020. Disponível em: https://bityli.com/QNzsQ. Acesso em: 10 nov. 2019.

SECRETARIA DA PREVIDÊNCIA. PEC 6/2019: nova previdência para o RPPS. Brasília, DF: MEC, 2019. Disponível em: https://bityli.com/ dOIEE. Acesso em: 10 nov. 2019. 